\title{
Construction of Automobile Service Engineering Under the Perspective of Engineering Education Accreditation
}

\author{
Dan Wei, Qihua Ma, Chenxi He, Yiping Luo \\ College of Automotive Engineering, Shanghai University of Engineering Science, Shanghai, China
}

\section{Email address:}

weiweidandan@163.com (Dan Wei)

\section{To cite this article:}

Dan Wei, Qihua Ma, Chenxi He, Yiping Luo. Construction of Automobile Service Engineering Under the Perspective of Engineering Education Accreditation. Science Journal of Education. Vol. 5, No. 3, 2017, pp. 86-89. doi: 10.11648/j.sjedu.20170503.12

Received: March 13, 2017; Accepted: March 22, 2017; Published: April 1, 2017

\begin{abstract}
In view of the engineering education accreditation concept, and according to the core values of higher engineering education professional accreditation, this article identifies the breakthrough in automobile service engineering professional training for positioning and post after well versed in technical secondary school degree. And the graduation requirements and ability oriented of the major is determined through the guidance of engineering education accreditation. This paper discusses the influence of engineering ability oriented education accreditation in automobile service engineering professional course system. The courses of automobile service engineering are accordance with orientation of engineering education accreditation ability.
\end{abstract}

Keywords: Engineering Accreditation, Automobile Service Engineering, Specialty Construction

\section{Introduction}

Engineering education accreditation is the current international advanced professional qualification management system, and it's the inevitable outcome of the development of times. In order to ensure the quality of engineering education and realize international certification of engineering education and engineer's qualification, the engineering education professional accreditation is implemented in China from the twentieth century. The concept of engineering education accreditation can be summarized as a center, two guidance, and three pillars. Its core idea "based on students", is centered on students. Accreditation evaluation is a kind of evaluation based on the output, it requires clear talent training goal of the major. It designs student ability according to the requirements of the target, and then determine the curriculum system based on the goal of student ability development. And realize the goal through the process of teaching goal. It makes "The student is the core" be true [1] [2].

The modern engineering education which demands engineering accreditation requires colleges and universities to enhance students' engineering consciousness, engineering quality, and engineering practice ability and strengthen the guiding ideology of cultivating creative spirit [3]. Colleges and universities in the training process of some applied strong professional (such as automobile service engineering) found that for students the requirement of some basic theory and the practiced ability restricted by the high school stage knowledge system, it is difficult to accommodate the undergraduate and professional knowledge, especially the practiced ability. Obviously, the cultivation of basic theory and the practiced ability need the strength which is customized before undergraduate to meet the needs of teaching requirements applications such as automobile service engineering undergraduate. At the same time, the students of secondary professional - automobile use and maintenance in the future career development process, even if they have a strong ability of hands-on practice, also limits the continuity of the career development in the future for the lack of specialized training, new theory, and high technology. Therefore, coordination of automobile service engineering undergraduate preparation stage and the cultivation of undergraduate students majoring in the process and the implementation through type training are a beneficial exploration and try. Obviously, this breakthrough is not a simple extension of study area transformation, but demand for the reform and innovation of technical secondary school three years of cultivation and four years of undergraduate course which reflecting through, systemic, comprehensive training purpose. The desired effect of the long educational system is achieved [4] [5].

The author in view of the Shanghai University of Engineering Science in automobile service engineering and 
Shanghai City Science and Technology School automobile application and service specialty in the engineering education accreditation under the perspective of the study well versed in specialty construction. This breakthrough in automobile service engineering construction should be based on the environment of school set up a scientific and reasonable training target. All qualified graduates should meet the graduation requirements of the development of the professional. And can let the spare capacity of the students get the room for improvement. The whole process of training to training target and graduation requirements is taken as a guide. Curriculum system, teachers and the conditions of software and hardware are specialized in the construction of the three pillars. First of all, you must set up reasonable curriculum system, and each teacher must be responsible for teaching new teaching activity's contribution to the training target. In the process of teaching quality monitoring and feedback mechanism is conducive to the continuous improvement of specialty construction. The combination of technical secondary school and college courses in automobile service engineering construction must first clear positioning and post oriented.

\section{Clarifying the Training Orientation and Faced Jobs in Automobile Service Engineering}

Automobile service engineering is one of new bachelor's degree programs in the Ministry of Education 2012 list of degrees, this degree has short developing time, however, it has great develop potential, nowadays there is more than 50 universities offer this new bachelor's degree. This degree has lot overlapping with other subjects and has strong applicability, so it is vital to clarify the training orientation and faced jobs of this combination of technical secondary school and college course in the degree of automobile service engineering [6].

Automobile service engineering is defined with many dynamic service activities base on an automobile. It not only has normal feature but also combined obvious characteristics of the intensive hi-tech application. The degree provides full-course technical service covered more than automotive logistics, trade, drive, maintenance, second-hand trade rating, and recycling. Therefore, automobile service engineering unlike with other servicing degrees, it should aim at training engineering students, and base at automobile service application technology, build a training system combined knowledge and capability, perfectly reflect the feature of blending engineering and humanities knowledge, linking theory with practice, cultivating multi-talented students. The globalization trends of the automobile industry makes great number of international famous international brands turn into Chinese local production trades and services, extended modern automobile service industry enormously, not only covered after-market services but also reach post-market and macro-service, such as consumer behavior research, market investigation and prediction, research and development of products, outsourcing, production Tests, accreditation and industrial policy, technical regulations, and the international trade environment research. This requires students of automobile service engineering must master broad knowledge and solid foundation, making The Graduate well-adapted and rather broad development space.

\section{Determine Graduation Requirements and Ability-Oriented Guide by Engineering Education Accreditation}

Engineering education accreditation requires major must have clear, definite and open graduation requirements which should support accomplish of training objectives major should certify the complete of training objectives by evaluating. The basic core value of engineering education professional accreditation is conformity accreditation. Engineering education professional accreditation is not a directive work in administrative machinery, but a conformity accreditation applied independently by Parties interested, it judge whether it matches the approval standards of engineering education major. The result of conformity accreditation is divided into four grades [7] [8]:

$P$ pass: Completely conform to the requirements of the engineering education professional accreditation standards;

$\mathrm{P} / \mathrm{C}$ pass: Already reach engineering education professional accreditation standards, but there is uncertainty, need constant attention and tracking check;

P/W pass: Basically meet the requirements of higher engineering education professional accreditation standards, but had shortcomings or problems, not enough to keep to the next watching period;

F failed: Do not meet the higher engineering education professional accreditation standards.

The conformity accreditation is not a features accreditation. It is not meant to recognize the strong point of this major, but to inspect whether this major meet the requirements of engineering education professional accreditation standard. Therefore, in the construction of this major must guide by engineering education accreditation standards, which can set graduation requirements and capability-oriented objectively and accurately.

Another core value of engineering education professional accreditation standard is competency-based approaching. It was translated from Professional accreditation standard principle in the Washington accord, meaning the engineering education (major) is based in quality of graduates. On the other hand, how is comprehensive quality of graduates? According to Professional accreditation standard principle in the Washington accord and practical condition of China, in our engineering education (major) approval standards, have multi-dimension demand, as after training in humanistic culture, scientific culture, engineering culture, making graduates developed innovate ability, engineering ability, management ability, communication ability, learning ability, development ability and etc. to creativity and effectively 
analyzing surrounding engineering activity. Professional development must base on graduates ability requirements of the accreditation, set up orderly practical and sustainable educational activity [9].

Automobile service engineering major face to automobile service industry, training talented person master engineering basic theoretical knowledge, basic knowledge of automotive engineering, inspection, diagnosis and maintenance, have strong ability of engineering application and practice, great spirit of team cooperation and innovation, and be equipped with professional accomplishment can swiftly adapted to the quick development of modern automobile service industry, possess senior professional skills certificate, can work on multiple job such as automobile after-sales service within Transportation and automobile service area [10].

The core of engineering education in automobile service engineering accreditation is surrounding students. Set up and utilize any high-quality education resources within and out campus, train auto service engineer that the society needs by systematically comprehensively and effectively engineering education activities. Therefore, combining with safety production demand and developing the trend of our country, blend education accreditation competency-based approaching in major development. Based on engineering education accreditation standards and Shanghai University of Engineering Science automobile service engineering major and the development situation of automobile operation and maintenance in Shanghai city science and technology school to set ability and quality as Graduation Requirements and ability training in automobile service engineering, specific information is as follows:

(1) The ability structure requirement: Have leadership, presentation skill, communicative ability and play a role in a team; Possess ability to use modern information technology to get any form of document that necessary, to communicate, compete and collaborate that cross culture; Possess ability to apply mathematics and natural science that needed; Possess great knowledge migration ability to apply proper theoretical knowledge and practical method, Have a certain analysis and solve practical problems ability in the field of automobile service engineering, have the knowledge and the ability to solving practical problems that necessary in this major, basic engineering innovation ability; Skillfully use modern advanced diagnosis technology and analysis problems. Have knowledge in economy and management, have engineering innovate awareness and basic ability to do so.

(2) The requirement in ability structure: have social science quality, sense of social responsibility, and engineering professional ethics, have ability to organize, express, and interpersonal, love their own work, have strong responsibility, knowing the importance of lifetime learning, have ability to study and self-developing continuously, acknowledge relevant regulation, knowing the impact of engineering activities, have creative spirit and self-employed skills, have international view.

The major implement construction of the combination of technical secondary school and college course is followed:

(1) Open up the way that allow Technical secondary school stage vehicle maintenance and mechanic test, combine practical teaching and Professional capacity requirements.

(2) Innovative professional practical part: move Automobile structure internship forward to Technical secondary school stage, enhance practical ability in technical secondary school stage, add in hobbies and interests of this major, and leave space for upcoming professional practice.

(3) Set up a platform for this vocational ability, achieve the practice system of cognizing practice, then station practice, then internship, then graduation project, making the contents of practical training more compact and objective.

(4) Come up with the special requirement of this major in enginery practical training, according to the professional characteristics come up with teaching content requirements for the manufacturing technology of internship, curriculum exercise of mechanical design etc. steps.

(5) Innovation and integration engineering practice platform: aside Racing Class College students' innovative practice platform driving function, expand in relevant automobile skills competition, making more students get intermediate skill certificate by the skill contest.

(6) Set up unite experiment platform between schools, provide conditions for students exploratory scientific research projects, meet the demand of students to new technologies.

Table 1. The combination of technical secondary school and college course - The list of automobile service engineering professional skills certificates.

\begin{tabular}{lllll}
\hline $\begin{array}{l}\text { Serial } \\
\text { number }\end{array}$ & Certificate Name & Certificate category & $\begin{array}{l}\text { Available } \\
\text { credits }\end{array}$ & Stage \\
\hline 1 & Primary Elementary Automobile Maintainer & National vocational qualification certificate & 1 & Secondary Specialized School \\
2 & Intermediate Automobile Maintainer & National vocational qualification certificate & 2 & Secondary Specialized School \\
3 & Senior Automobile Maintainer & National vocational qualification certificate & 2 & Undergraduate Years \\
4 & Primary Auto repair metaler & National vocational qualification certificate & 1 & Secondary Specialized School \\
5 & Primary Vehicle Repair and Maintenance & National vocational qualification certificate & 1 & Secondary Specialized School \\
6 & Junior Automobile marketing division & Special skill certificate & 1 & Secondary Specialized School \\
7 & Senior Automobile marketing division & Special skill certificate & 2 & Undergraduate Years \\
8 & Second-hand Car Appraiser & Special skill certificate & 2 & Undergraduate Years \\
\hline
\end{tabular}


According to the capability requirement and occupation of the combination of technical secondary school and college course, Students in this major must obtain credit requirement of the second classroom in the major teaching plan by getting Professional skills certificate relevant of this major. The combination of technical secondary school and college course-Automobile service engineering major skill certificate list is shown as table 1 .

\section{Conclusions}

In the background of engineering education accreditation, the major contraction of Automobile service engineering must base on the Concept that student-centered, focus on ability training, design thought powered by improving engineering practice and innovation capacity, improve practical college teaching goal, definite Develop orientation and position, and must base on engineering education accreditation. And Fully implement Engineering education accreditation in Automobile service engineering major curriculum system, improve major teaching quality monitoring system, Enhance the level of specialty construction with steady steps.

\section{Acknowledgements}

The project is supported by the fund of important teaching and reforming project of Shanghai undergraduate university "The training mode reform and practice of the combination of technical secondary school and college course in automobile service engineering major", Shanghai training funds for young teacher (No. ZZGCD15040) and the funds of "Intelligent Transportation System" course construction from SUES (k2017060002).

\section{References}

[1] Rahel S.: Accreditation and quality assurance in the Egyptian higher education system. Quality Assurance in Education, 2015, 149-165.
[2] Jun Z., Carlos F.: Business school accreditation in the changing global marketplace: A comparative study of the agencies and their competitive strategies. Journal of International Education in Business, 2016, 52-69.

[3] Kang X.: An Analysis on the Differences between the Specialty-Education of Sino-American Construction Engineering Management. Engineering Education and Management. 2011, 143-148.

[4] Wang, Y., Wang, N.: Status and Development of Engineering Management. Engineering Science, 11-17 (June 2006).

[5] Li, X.: Reflection on Undergraduate teaching and training program setting of Engineering Management. Project Management Technology, 2008, 68-71.

[6] Zhang, J., Fang, H.: Strengthening the Open Experimental Platform Building, Promoting Student Innovation Ability Training. Modern Educational Technology, 2009, 19 (7), 132134.

[7] Ministry of education. Teaching quality and teaching reform project opinion of higher education from ministry of finance. Ministry of Education 1. 2007.

[8] Scott, F., Stuart, D. G., Stephanie J. W.: Dilettantes, discipline and discourse: requirements management for construction. Engineering, Construction and Architectural Management, 2003, 354-367.

[9] Hana K., Chris B.: School discipline, investment, competitiveness and mediating educational performance. International Journal of Educational Management, 2017, 293-319.

[10] Qiang D., Michèle E. M. A.: The characteristics and historical development path of the globalizing Chinese automobile industry. Journal of Technology Management in China, 2013, 83-104. 